Yelisman Zebua ${ }^{1}$

\title{
MEDIA POWERPOINT BERBASIS VIDEO TERHADAP HASIL BELAJAR MATERI KESELAMATAN DAN KESEHATAN KERJA (K3) PADA MAHASISWA PENDIDIKAN TEKNIK BANGUNAN IKIP GUNUNGSITOLI
}

\begin{abstract}
Abstrak
Selain strategi dan model pembelajaran, media pembelajaran merupakan salah satu faktor yang mempengaruhi kegiatan pendidikan dan pembelajaran. Media powerpoint berbasis video digunakan agar proses pembelajaran menjadi lebih menarik, menyenangkan dan mudah dipahami. Tujuan penelitian ini adalah menggunakan media Powerpoint berbasis video untuk memperoleh informasi tentang hasil belajar, proses pembelajaran, dan reaksi mahasiswa. Penelitian ini dilaksanakan di IKIP Gunungsitoli dengan sasaran mahasiswa semester gasal yang berjumlah 27 mahasiswa. Variabel yang diteliti yakni hasil belajar mahasiswa, proses pembelajaran, serta respon mahasiswa. Pengumpulan data hasil belajar dengan tes uraian, proses pembelajaran dengan pengamatan kelas, dan respons mahasiswa dengan kuesioner (angket) respons dalam menggunakan media powerpoint berbasis video. Hasil belajar mahasiswa mendapatkan nilai rata-rata sebesar 80,7 dengan ketuntasan belajar mahasiswa mencapai $81 \%$, untuk proses pembelajaran berjalan lancar dengan nilai rerata 4,51 dari skor maksimum 5 . Mahasiswa merespons baik dengan nilai sebesar 84,96 dari nilai maksimal 100. Disimpulkan bahwa pembelajaran dengan menggunakan media powerpoint berbasis video memiliki peran positif terhadap hasil belajar mahasiswa.
\end{abstract}

Kata Kunci: Powerpoint Berbasis Video, Hasil Belajar Mahasiswa, Keterlaksanaan Pembelajaran.

\section{Abstract}

Medium teaching is one of the factors that influence the learning activities in addition to strategies and learning models. Video-based powerpoint as a learning medium plays a role in the learning process to become more interesting, easy to understand, and fun. The purpose of this study is to obtain information about learning outcomes, implementation of learning, and student responses using video-based powerpoint as a medium. This research was conducted at Building engineering education IKIP Gunungsitoli with target is 1st semester which amounted 25 students. Research variables include student learning outcomes, implementation of learning, and student responses. Data collection for learning outcomes using a description test, learning implementation using classroom observation, and student responses using a questionnaire sheet when using video-based powerpoint as a medium. Based on the result of student learning test gets average 81,46 with student's learning completeness reach $80,00 \%$, implementation of learning gets average 4,51 with maximal score 5, and student response gets average $84,96 \%$. So, it can be concluded that learning by using video-based powerpoint as a medium gets positive results on student learning.

Keywords: Powerpoint-based Video, Student Learning Outcomes, Implementaion of Learning

\footnotetext{
${ }^{1}$ Prodi Pendidikan Teknik Bangunan, IKIP Gunungsitoli

Email: yelyszeb@gmail.com
} 


\section{PENDAHULUAN}

Mata Kuliah Keselamatan dan Kesehatan Kerja Program Pendidikan Teknik Bangunan IKIP Gunung Sitoli merupakan mata kuliah yang menjamin keutuhan dan kesempurnaan baik jasmani maupun rohani, tenaga kerja pada khususnya dan masyarakat pada umumnya terhadap hasil karya dan budayanya menuju masyarakat adil dan makmur. Secara ilmu pengetahuan dan penerapannya dalam usaha mencegah terjadinya kecelakaan dan penyakit akibat kerja. Tujuan dari kursus ini adalah untuk mengajarkan siswa bagaimana melindungi kesehatan, keselamatan dan perlindungan pekerja, memastikan keamanan alat yang mereka gunakan dan memastikan proses produksi yang aman dan lancar.

Pendidikan Teknik Bangunan IKIP Gunungsitoli sebagai salah satu lembaga yang menghasilkan calon guru dan dimungkinkan juga sebagai tenaga kerja di industri sehingga diharapkan mampu mengikuti tuntutan dalam dunia kerja. Di dalam lingkungan kerja selain ketrampilan dan pengetahuan juga dibutuhkan kerjasama (teamwork) untuk menyelesaikan suatu permasalahan (Fajra, dkk., 2020; Dakhi, dkk., 2020). Saat ini, kemampuan tentang K3 peserta didik dalam kebanyakan institusi pendidikan kurang diperhatikan. Karakter kerja yang dibutuhkan dunia kerja meliputi: etika kerja, rasa keingintahuan, sifat dapat dipercaya, disiplin diri, kejujuran, komitmen, tanggung jawab, respek terhadap diri sendiri dan orang lain, toleransi, kerja keras, hubungan kerja yang baik, integritas, perilaku yang baik, komunikasi kegigihan, motivasi kerja tinggi, kerjasama yang baik, inisiatif, keberanian moral, kerajinan, daya adaptasi, pengendalian diri, pembelajar yang cepat, keinginan untuk belajar hal-hal yang baru, kemampuan cara belajar, keluwesan dan kewirausahaan (Sarumaha, dkk., 2018; Zagoto \& Dakhi, 2018; Zagoto \& Yarni, 2019; Srimaya, 2017).

Pada pelaksanaan mata kuliah Keselamatan dan Kesehatan Kerja, diperlukan peran media powerpoint berbasis video yang sesuai dengan pembelajaran era digital masa kini (Rezeki \& Ishafit, 2017). Pembelajaran menggunakan media powerpoint berbasis video diharapkan dapat memungkinkan mahasiswa berpartisipasi aktif dalam proses pembelajaran dengan menjawab pertanyaan. Selain itu, media yang digunakan dalam kegiatan pembelajaran juga banyak berpengaruh agar proses pembelajaran menjadi lebih menarik, mudah dipahami, dan menyenangkan. Powerpoint adalah program aplikasi presentasi yang dibuat oleh Microsoft Corporation, seperti halnya perangkat lunak pengolah presentasi lainnya, PowerPoint dapat memposisikan teks, grafik, video, suara, dan objek lain pada satu atau beberapa halaman yang disebut slide (Agustina, 2012). Powerpoint merupakan bagian dari keseluruhan presentasi maupun menjadi satu-satunya sarana penyampaian informasi. Powerpoint dapat pula menjadi media utama penyampaian presentasi, misalnya pada presentasi produk/iklan mini, profil perusahaan, dan presentasi online (Fadhli, 2016). Presentasi dapat disertai dengan narasi dan ilustrasi suara, musik, atau video yang diputar selama presentasi. Keuntungan terbesar dari program ini adalah tampilan ikon yang mudah saat membuat presentasi. Selain itu, PowerPoint sangat mudah dioperasikan, sangat sederhana dan tidak memerlukan biaya mahal serta tidak memerlukan persiapan yang rumit (Diah \& Nita, 2018).

Video dapat menggambarkan objek bergerak bersama dengan suara atau suara alamiah yang sesuai. Kemampuan video dalam menangkap gambar dan suara secara langsung memberikan daya tarik tersendiri (Solihin, 2010; Zagoto, 2018). Media ini biasa digunakan untuk hiburan, dokumentasi dan pendidikan. Video dapat menampilkan informasi, menjelaskan proses, menjelaskan konsep kompleks, mengajarkan keterampilan, mengurangi atau menambah waktu, dan memengaruhi sikap. Program video dapat digunakan dalam program pembelajaran, karena dapat memberikan pengalaman yang tidak terduga bagi mahasiswa. Selain itu, program video dapat digabungkan dengan animasi dan pengaturan kecepatan untuk mendemonstrasikan perubahan seiring waktu.

Beberapa manfaat dalam penggunaan media video dalam proses belajar mahasiswa, yaitu:

1. Pembelajaran akan lebih menarik perhatian mahasiswa yang dapat memotivasi mereka untuk belajar. 
2. Metode mengajar akan lebih bervariasi, tidak semata-mata komunikasi verbal melalui penuturan kata-kata oleh guru, sehingga mahasiswa tidak bosan dan guru tidak kehabisan tenaga, apalagi kalau guru mengajar pada setiap jam pelajaran.

3. Penggunaan video untuk tujuan kognitif dapat digunakan untuk hal-hal yang menyangkut kemampuan mengenal kembali dan kemampuan memberikan rangsangan berupa gerak yang serasi dan mengajarkan pengenalan makna sebuah konsep serta aturan dan prinsip.

4. Video yang mengandung nilai-nilai positif dapat mengundang pemikiran dan diskusi dalam kelompok siswa.

\section{METODE PENELITIAN}

Penelitian ini dilakukan untuk mengetahui peran penggunaan media powerpoint berbasis video terhadap hasil belajar mahasiswa dalam materi Keselamatan dan Kesehatan Kerja (K3). Penelitian ini dilaksanakan di Pendidikan Teknik Bangunan IKIP Gunungsitoli. Jenis penelitian ini adalah penelitian kuantitatif dan menggunakan metode penelitian pre-experimental design, menggunakan metode penelitian pre-experimental design dengan bentuk one shoot case study

Tabel 1. Desain Penelitian

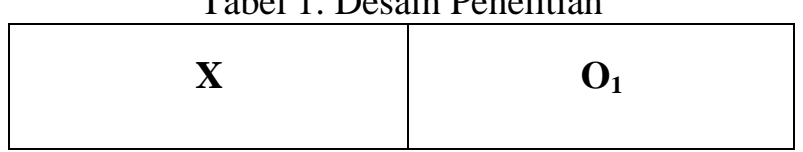

Sumber: Sugiyono, 2013

Keterangan:

$\mathrm{X}$ : Treatment (variabel independen) yang diberikan kepada mahasiswa berupa penggunaan media powerpoint berbasis video.

$\mathrm{O}_{1}$ : Posttest (variabel dependen) diberikan kepada kelas eksperimen setelah mendapat treatment.

Variabel penelitian meliputi (1) variabel bebas yaitu penggunaan media powerpoint berbasis video dan (2) variabel terikat yaitu hasil belajar mahasiswa K3 yang diperoleh dari hasil tes (posttest). Instrumen penelitian berupa tes, hasil belajar, lembar observasi pelaksanaan pembelajaran dan angket respon mahasiswa.

\section{HASIL DAN PEMBAHASAN}

1. Hasil Belajar

Berdasarkan perhitungan, dapat diketahui rata-rata hasil belajar mahasiswa yang diperoleh dengan menggunakan rumus:

$$
\text { Rata-rata }=\frac{\text { total skor }}{\text { jumlah siswa }}=\frac{2180}{27}=80,7
$$

Mahasiswa yang dikatakan tuntas apabila mendapatkan nilai $\geq 75$, sedangkan mahasiswa yang mendapatkan nilai $<75$ dikatakan tidak tuntas. Untuk mengetahui persentase ketuntasan belajar mahasiswa dapat diketahui dengan menggunakan rumus di bawah ini:

$$
\begin{gathered}
\text { Mahasiswa yang tuntas }=22 \text { mahasiswa } \\
\text { Mahasiswa yang tidak tuntas }=5 \text { mahasiswa } \\
\text { Persentase Tuntas }=\frac{22}{27} \times 100 \%=81 \% \\
\text { Persentase Tidak Tuntas }=\frac{5}{27} \times 100 \%=19 \%
\end{gathered}
$$


Dari perhitungan di atas dapat disimpulkan bahwa rata-rata nilai yang didapat mahasiswa sebesar 80,7. Persentase ketuntasan belajar mahasiswa dengan nilai $\geq 75$ berjumlah 22 mahasiswa dari total mahasiswa, sedangkan persentase mahasiswa yang belum tuntas belajarnya dengan nilai $<75$ berjumlah 5 mahasiswa dari total mahasiswa. Secara keseluruhan pembelajaran dengan menggunakan media powerpoint berbasis video pada mata kuliah Keselamatan dan Kesehatan Kerja (K3) Pendidikan Teknik Bangunan berlangsung sangat lancar dan baik. Ketuntasan belajar mahasiswa yang dicapai sebesar $81 \%$ ini termasuk dalam kategori baik dan kelas dikatakan tuntas belajar (ketuntasan klasikal) bila mendapat nilai lebih dari $75 \%$ mahasiswa mencapai ketuntasan belajar.

\section{Keterlaksanaan Pembelajaran}

Hasil keterlaksanaan pembelajaran dapat dilihat pada analisa data dan pembahasannya berikut:

\section{a. Pertemuan I}

Berdasarkan hasil pengamatan observer, dapat diketahui jumlah observer $(\mathrm{N})=3$, skor maksimum tiap indikator $(\mathrm{I})=5$, dan jumlah indikator $(\mathrm{r})=21$. Nilai pengamatan yang diperoleh sebesar 252 dari total skor 315 . Berikut ini merupakan hasil pengamatan keterlaksanaan pembelajaran pada pertemuan I.

Tabel 1. Hasil Pengamatan Keterlaksanaan Pembelajaran Pertemuan I

\begin{tabular}{|l|c|c|c|c|}
\hline \multirow{2}{*}{ Skenario } & \multicolumn{1}{|c|}{ Skor Observer } & \multirow{2}{*}{ Jumlah } \\
\cline { 2 - 4 } & $\mathbf{1}$ & $\mathbf{2}$ & $\mathbf{3}$ & \\
\hline Pendahuluan & 18 & 16 & 17 & 51 \\
\hline Kegiatan Inti & 53 & 54 & 54 & 160 \\
\hline Penutup & 14 & 13 & 14 & 41 \\
\hline \multicolumn{3}{|c|}{ Total } & 252 \\
\hline
\end{tabular}

Berdasarkan tabel di atas, dapat diketahui hasil pengamatan keterlaksanaan pembelajaran, yakni:

$$
\text { Hasil }=\frac{\sum f}{N . I . r}=\frac{252}{3(5)(21)}=0,8
$$

Untuk menentukan kategori penilaian maka dikonversi dalam bentuk persentase, yaitu $0,8 \times 100 \%=80 \%$. Hasil persentase keterlaksanaan pembelajaran pada pertemuan I sebesar $80,00 \%$ dan masuk pada kategori baik meskipun seharusnya bisa mendapatkan persentase yang lebih. Hal ini disebabkan masih banyak keterbatasan yang ditemukan pada pertemuan I dalam proses pembelajaran.

\section{b. Pertemuan II}

Berdasarkan hasil pengamatan observer, dapat diketahui jumlah observer $(\mathrm{N})=3$, skor maksimum tiap indikator $(\mathrm{I})=5$, dan jumlah indikator $(\mathrm{r})=17$. Nilai pengamatan yang diperoleh sebesar 230 dari total skor 255. Berikut ini merupakan hasil pengamatan keterlaksanaan pembelajaran pada pertemuan II. 
Tabel 2. Hasil Pengamatan Keterlaksanaan Pembelajaran Pertemuan II

\begin{tabular}{|l|c|c|c|c|}
\hline \multirow{2}{*}{ Skenario } & \multicolumn{3}{|c|}{ Skor Observer } & \multirow{2}{*}{ Jumlah } \\
\cline { 2 - 5 } & $\mathbf{1}$ & $\mathbf{2}$ & $\mathbf{3}$ & \\
\hline Pendahuluan & 19 & 18 & 19 & 56 \\
\hline Kegiatan Inti & 43 & 43 & 45 & 131 \\
\hline Penutup & 14 & 14 & 15 & 43 \\
\hline \multicolumn{4}{|c}{ Total } & 230 \\
\hline
\end{tabular}

Berdasarkan tabel di atas, dapat diketahui hasil pengamatan keterlaksanaan pembelajaran dengan menggunakan rumus:

$$
\text { Hasil }=\frac{\sum f}{N . I . r}=\frac{230}{3(5)(17)}=0,9
$$

Untuk menentukan kategori penilaian maka dikonversi dalam bentuk persentase, yaitu $0,9 \times 100 \%=90 \%$. hasil keterlaksanaan pembelajaran (pertemuan II) mendapatkan persentase sebesar $90,00 \%$ dan masuk pada kategori sangat baik, karena berada diantara $81,00 \%-100,00 \%$.

Berdasarkan hasil pengamatan keterlaksanaan pembelajaran dengan menggunakan media powerpoint berbasis video pada mata kuliah Keselamatan dan Kesehatan Kerja (K3) Pendidikan Teknik Bangunan yang dilakukan, dapat disimpulkan pada gamar berikut:

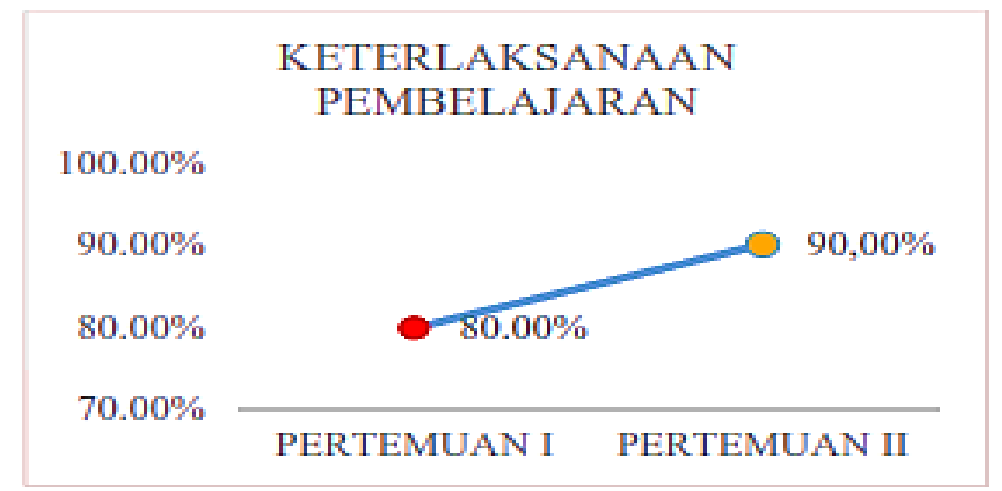

Gambar 1. Diagram Hasil Keterlaksanaan Pembelajaran

Hasil persentase keterlaksanaan pembelajaran dengan menggunakan media powerpoint berbasis video pada mata kuliah Keselamatan dan Kesehatan Kerja (K3) Pendidikan Teknik Bangunan dari pertemuan I dan pertemuan II terjadi peningkatan, yang artinya pada setiap pertemuan aktivitas guru dan mahasiswa semakin baik. Secara keseluruhan pembelajaran dengan menggunakan media powerpoint berbasis video pada mata kuliah Keselamatan dan Kesehatan Kerja (K3) Pendidikan Teknik Bangunan berlangsung sangat baik, karena hasil nilai yang didapat berdasarkan pertemuan II keterlaksanaan pembelajaran pada kelas tersebut yaitu sebesar 90,00\% dan termasuk dalam kategori sangat baik karena berada diantara $81,00 \%-100,00 \%$.

\section{c. Respon Mahasiswa}

Hasil respon mahasiswa pada pembelajaran dengan menggunakan media powerpoint berbasis video pada mata kuliah Keselamatan dan Kesehatan Kerja (K3) Pendidikan Teknik Bangunan dapat dilihat pada analisa dan pembahasan berikut: 
Tabel 3. Hasil Tiap Deskripsi Respons Mahasiswa

\begin{tabular}{|c|c|c|c|}
\hline Deskripsi & $\begin{array}{c}\text { Bobot } \\
\text { Skor }\end{array}$ & Jumlah & Total \\
\hline Sangat Setuju & 5 & 101 & 504 \\
\hline Setuju & 4 & 284 & 1141 \\
\hline Ragu-ragu & 3 & 83 & 246 \\
\hline Tidak Setuju & 2 & 17 & 33 \\
\hline Sangat Tidak Setuju & 1 & 11 & 11 \\
\hline \multicolumn{3}{|c|}{ Jumlah Total } & 1935 \\
\hline
\end{tabular}

Berdasarkan tabel di atas, dapat diketahui jumlah total respons yang diperoleh sebesar 1935. Untuk menentukan kategori penilaian tiap deskripsi maka dikonversi dalam bentuk persentase, dengan menggunakan rumus:

$$
\% \text { Tiap deskripsi }=\frac{\sum \text { jawaban deskripsi }}{\sum \text { jawaban }} \times 100 \%
$$

Untuk lebih jelasnya mengenai hasil respons mahasiswa tentang pembelajaran dengan menggunakan media powerpoint berbasis video dalam materi Keselamatan dan Kesehatan Kerja (K3) dapat dilihat pada gambar berikut:

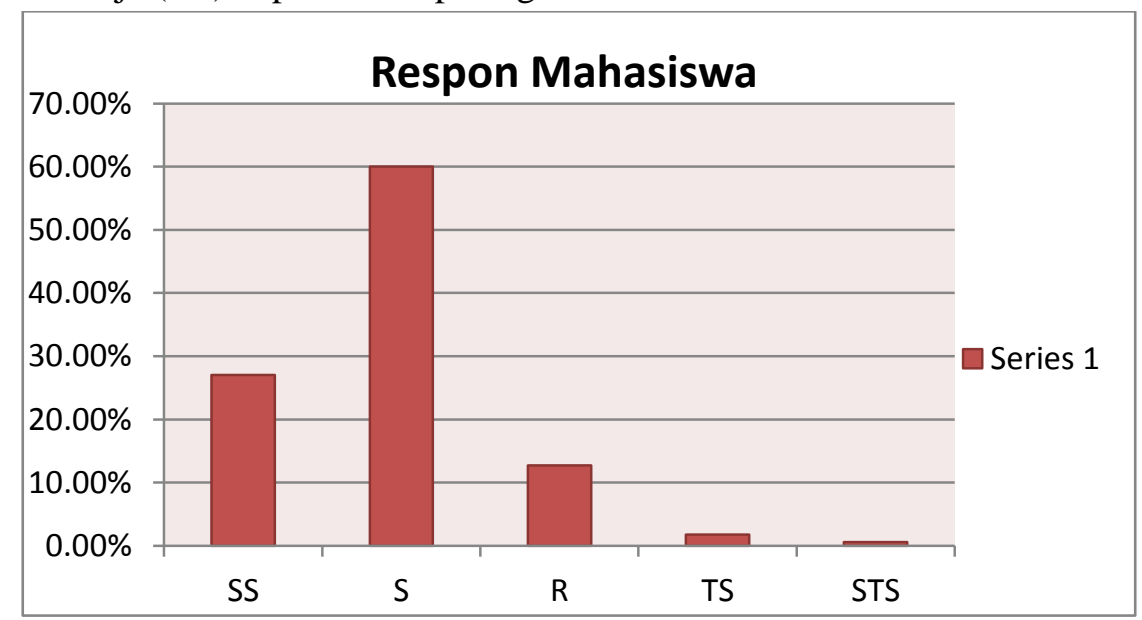

Gambar 2. Hasil Respon Mahasiswa

Dari perhitungan di atas, dapat disimpulkan bahwa hasil respon mahasiswa didapat dari penjumlahan persentase deskripsi Sangat Setuju (SS) sebesar 27,08\% dan Setuju (S) sebesar 59,98\%, sehingga mendapatkan persentase sebesar 84,96\% dan masuk pada kategori sangat setuju, karena berada diantara $81 \%-100 \%$, artinya respons mahasiswa mengenai pembelajaran dengan menggunakan media powerpoint berbasis video pada mata kuliah pelajaran Keselamatan dan Kesehatan Kerja (K3) dapat diterima oleh mahasiswa.

\section{SIMPULAN}

Berdasarkan hasil analisis data dan pembahasan pada penelitian ini, diperoleh simpulan sebagai berikut:

1. Nilai hasil tes belajar mahasiswa $81 \%$ dinyatakan tuntas dengan hasil belajar rata-rata sebesar 80,7. Sehingga dapat disimpulkan bahwa hasil belajar pada pembelajaran dengan menggunakan media powerpoint berbasis video pada mata kuliah Keselamatan 
dan Kesehatan Kerja (K3) Pendidikan Teknik Bangunan dinyatakan tuntas dan termasuk dalam kategori baik.

2. Hasil pengamatan keterlaksanaan pembelajaran pada pertemuan I mendapatkan nilai sebesar 252 dari total nilai 315 dengan persentase sebesar $80 \%$ dan pada pertemuan II terjadi peningkatan dari hasil analisa dan perbaikan pada pertemuan I yaitu mendapatkan nilai 230 dari total nilai 255 dengan persentase sebesar 90\%. Sehingga dapat disimpulkan bahwa keterlaksanaan pembelajaran dengan menggunakan media powerpoint berbasis pada mata kuliah Keselamatan dan Kesehatan Kerja (K3) Pendidikan Teknik Bangunan termasuk dalam kategori sangat baik.

3. Pembelajaran dengan menggunakan media powerpoint berbasis video disenangi mahasiswa, dengan $84,96 \%$ mengatakan sangat setuju dilaksanakan

\section{DAFTAR PUSTAKA}

Agustina, A. (2012). Pengembangan Media Pembelajaran Video untuk Melatih Kemampuan Memecahkan Masalah pada Materi Larutan Asam Basa. UNESA Journal of Chemical Education, 1(1).

Diah, I., \& Nita, S. (2018). Media embelajaran Berbasis Multimedia Interaktif untuk Meningkatkan Pemahaman Konsep Mahasiswa. Journal of Computer and Information Technology, 1(2), 68-75.

Dakhi, O., Jama, J., Irfan, D., Ambiyar, Ishak. (2020). Blended Learning: A 21st Century Learning Model At College. International Journal Of Multi Science, 1(8), 50-65.

Fadhli, M. (2016). Pengembangan Media Pembelajaran Berbasis Video Kelas IV Sekolah Dasar. Jurnal Dimensi Pendidikan dan Pembelajaran, 3(1), 2433.

Fajra, M., Suparno, Sukardi, Ambiyar, Novalinda, R. (2020). Project-Based Learning Innovation To Improve The Suitability Of Productive Competencies In Vocational School With The Needs Of The World Of Work. International Journal Of Multi Science, $1(8), 1-11$.

Rezeki, S., \& Ishafit. (2017). Pengembangan Media Pembelajaran Interaktif untuk Sekolah Menengah Atas Kelas XI pada Pokok Bahasan Momentum. JPPPF-Jurnal Penelitian \& Pengembangan Pendidikan Fisika, 3(1), 29-34.

Sarumaha, R., Harefa, D., \& Zagoto, M.M. (2018). Upaya Meningkatkan Kemampuan Pemahaman Konsep geometri Transformasi Refleksi Siswa Kelas XII-IPA-B SMA Kampus Telukdalam Melalui Model Pembelajaran Discovery learning Berbantuan Media Kertas Milimeter. Jurnal Education and development, Vol.6 No.1, 90-96, Institut Pendidikan Tapanuli Selatan, Padangsidimpuan. https://doi.org/10.37081/ed.v6i1.668

Sholihin, K. H. (2010). Pengembangan Media Pembelajaran Menggunakan Powerpoint pada Mata Diklat Teknik Bubut Di SMK Negeri II Pengasih. Yogyakarta: Universitas Negeri Yogyakarta.

Srimaya. (2017). Efektivitas Media Pembelajaran Powerpoint untuk Meningkatkan Motivasi dan Hasil Belajar Biologi siswa. Jurnal Biotek, 5 (1).

Sugiyono. (2013). Penelitian Pendidikan Pendekatan Kuantitatif, Kualitatif dan $R \& D$. Bandung: Alfabeta.

Zagoto, Maria M. (2018). Pengembangan Perangkat Pembelajaran Matematika Berbasis Realistic Mathematic Educations Untuk Siswa Kelas V Sekolah Dasar, Jurnal Education And Development, vol. 3, no. 1, p. 53, Feb. 2018. https://doi.org/10.37081/ed.v3i1.139

Zagoto, Maria M., Nevi Yarni \& Dakhi, O (2019). Perbedaan Individu dari Gaya Belajarnya Serta Implikasinya Dalam Pembelajaran. Jurnal Review Pendidikan dan Pengajaran, 2(2), 259-265.

Zagoto, Maria M. \& Dakhi, O (2018). Pengembangan Perangkat Pembelajaran Matematika Peminatan Berbasis Pendekatan Saintifik Untuk Siswa Kelas XI Sekolah Menengah Atas. Jurnal Review SPendidikan dan Pengajaran, 1(1), 157-170. 